\title{
Physical factors affecting the production of organic solvent-tolerant protease by Pseudomonas aeruginosa strain $\mathrm{K}$
}

\begin{abstract}
The physical factors affecting the production of an organic solvent-tolerant protease from Pseudomonas aeruginosa strain $\mathrm{K}$ was investigated. Growth and protease production were detected from 37 to $45{ }^{\circ} \mathrm{C}$ with $37{ }^{\circ} \mathrm{C}$ being the optimum temperature for $\mathrm{P}$. aeruginosa. Maximum enzyme activity was achieved at static conditions with $4.0 \%$ (v/v) inoculum. Shifting the culture from stationary to shaking condition decreased the protease production $(6.0-10.0 \% \mathrm{v} / \mathrm{v})$. Extracellular organic solvent-tolerant protease was detected over a broad $\mathrm{pH}$ range from 6.0 to 9.0. However, the highest yield of protease was observed at $\mathrm{pH}$ 7.0. Neutral media increased the protease production compared to acidic or alkaline media
\end{abstract}

Keyword: Organic solvent-tolerant protease, Physical factors, Pseudomonas aeruginosa 